\title{
Combining Essential Oils of Piper betle and Myristica fragrans for Enhanced Antimicrobial Properties
}

\author{
SIONG FONG SIM ${ }^{1, *}$, FAZIA MOHD SINANG ${ }^{1}$, DIANA KERTINI ${ }^{1}$, FELECIA \\ COLLICK $^{1}$, MELISSA EDWARD DANKAN ${ }^{2}$, VANESSA RENTING NIXION LUNCHA ${ }^{2}$ \\ $\&$ NOOR SYAZANA ABDUL MAJID ${ }^{2}$ \\ ${ }^{1}$ Department of Chemistry, Universiti Malaysia Sarawak, Faculty of Resource Science and Technology, \\ 94300 Kota Samarahan, Sarawak, Malaysia; ${ }^{2}$ MARA Junior Science College, Jalan Sultan Tengah, \\ Petra Jaya, 93050 Kuching, Sarawak, Malaysia
}

\begin{abstract}
This paper reports the chemical compositions and antimicrobial activity of essential oils extracted from Myristica fragrans and Piper betle in individual and combined fractions. Enhanced antimicrobial activity is anticipated when the volatile oils are combined as compounds present in different extracts could complement each other resulting in synergistic effect offering a broader spectrum of microbial resistance. The GC-MS analysis indicates that chemical compositions of $M$. fragrans and $P$. betle vary with $M$. fragrans containing more early-eluting compounds. The combined extract is characterised by compounds present in both extracts, some appear to co-elute in the mixture. The antimicrobial activity of the single and combined extracts against Staphylococcus aureus, Escherichia coli and Aspergillus flavus were evaluated. P. betle demonstrates stronger antimicrobial activity than $M$. fragrans; the combined extract exhibit improved performance especially on $A$. flavus.
\end{abstract}

Keywords: Essential oils, antibacterial, antifungal, $M$. fragrans, $P$. betle

\section{INTRODUCTION}

Essential oil has long been recognised for its antimicrobial activity primarily as antibacterial and antifungal agent. A study by Pawar \& Nabar (2010) evidenced that mixing the essential oil could increase the coverage of microbial resistance. The synergistic and additive antimicrobial effect was similarly demonstrated elsewhere (Lachowicz et al. 1998; Das et al. 2012; Nguefack et al. 2012). Hypothetically, if the volatile oil extracted from two plants exerts antibacterial and antifungal activity, respectively, the combined extract would be more potent than the individual fraction. Likewise, if the extracts from both plants exhibit positive response against two different bacterial strains, the blended fraction is anticipated with a greater spectrum of microbial resistance. In this paper, we attempt to evaluate the chemical composition and antimicrobial activity of the single and blended essential oils of $P$. betle and $M$. fragrans. Essential oils from both plants have been known with promising antimicrobial properties nevertheless there is no information on the blended extract as yet (Dorman \& Deans, 2000; Datta et al. 2012; Suprapta \& Khalimi, 2012; Arambewela et al. 2005; Muchtaridi et al. 2011).

\section{MATERIALS \& METHODS}

\subsection{Extraction of essential oil}

The fresh $P$. betle leaves and $M$. fragrans seeds were cut into smaller pieces and subjected to hydrodistillation using a Clevenger apparatus according to Meshkatalsadat et al. (2009). Approximately $100 \mathrm{~g}$ of samples were placed into a $2 \mathrm{~L}$ flat bottom flask with $1.5 \mathrm{~L}$ distilled water and several granules of anti-bumping agents. The samples were hydrodistilled for 6 hrs and the volatile oil extracted was dried with a small amount of anhydrous sodium sulphate.

*Corresponding author: sfsim@frst.unimas.my 


\subsection{Chemical analysis}

Two milligrams of essential oil was dissolved in $2 \mathrm{~mL}$ of dichloromethane (DCM) for gas chromatography mass spectrometry (GC-MS) analysis. For the combined extract, $1 \mathrm{~mL}$ of the dissolved volatile oil of $P$. betle and $M$. fragrans was drawn and mixed. The essential oil was analysed on a Shidmazu GC-MS system model QP500. A medium polarity capillary column; BPX-5 column $(29.5 \mathrm{~m} \times$ $0.25 \mathrm{~mm}$ ), with film thickness of $0.25 \mu \mathrm{m}$ was used with helium as the carrier gas. One microlitre of sample was injected using splitless injection according to the following scheme: $50{ }^{\circ} \mathrm{C}$ for 5 mins with $6.5^{\circ} \mathrm{C} / \mathrm{min}$ up to $280{ }^{\circ} \mathrm{C}$. The final temperature was held for 10 mins. The total runtime for each sample was 50 mins. For MS detection, the mass fragments were detected between 40 and 1000 amu. The ion source temperature was $200{ }^{\circ} \mathrm{C}$. Note that the detector was activated after 10 mins. The compounds detected were identified based on $90 \%$ correlation of the mass spectrum with the pattern of the NIST library (Adams, 1995).

\subsection{Antibacterial activity}

$S$. aureus and E. coli, representative of grampositive and gram negative culture, respectively, were tested on the single and blended essential oil. The bacterial cultures were wild type bacteria confirmed by sequencing. The active cultures were prepared by inoculating fresh Mueller Hinton Broth (MHB) with single colony bacteria streaked from stock cultures and incubated at $37{ }^{\circ} \mathrm{C}$ overnight. A standardised optical density (OD) at $600 \mathrm{~nm}$ of 0.60 was attained. The antibacterial activity was determined using the disc diffusion method. The agar plates were prepared and swabbed with the bacterial culture using sterile cotton uniformly. A $10 \mu \mathrm{L}$ of essential oil (single and blended) at concentrations $10 \mathrm{mg} / \mathrm{mL}, 20 \mathrm{mg} / \mathrm{mL}$ and 50 $\mathrm{mg} / \mathrm{mL}$, prepared in $30 \%$ dimethyl sulfoxide (DMSO), were loaded on sterile filter paper discs of $6 \mathrm{~mm}$ in duplicates. The disc was placed on the surface medium and the plates were incubated at $37{ }^{\circ} \mathrm{C}$ for $24 \mathrm{hrs}$. The inhibition zones were measured in milimeter. Commercial antibiotic, streptomycin and penicillin, were used as positive control and DMSO was used as negative control. The method is described in Emami et al. (2006).

\subsection{Antifungal activity}

The antifungal activity was tested on A. flavus. A $100 \mu \mathrm{L}$ essential oil $(10 \mathrm{mg} / \mathrm{mL}, 20 \mathrm{mg} / \mathrm{mL}$ and $50 \mathrm{mg} / \mathrm{mL}$, respectively) was spread onto petri dishes of potato dextrose agar (PDA). A circular block of mycelia from the freshly prepared stock culture was punched and placed onto the plates. The diameter of the fungus was obtained on the fifth day after incubation at $30^{\circ} \mathrm{C}$ as a measure of growth (Serrano et al. 2004). Note that in this study only the negative control of DMSO was used.

\section{RESULTS \& DISCUSSION}

Figure 1 illustrates the chromatograms of the single and combined essential oils of $P$. betle and $M$. fragrans. Visually, the compounds eluted at the earlier retention time in $M$. fragrans, between 10 and 15 mins, are not found in $P$. betle; the peaks detected after 23 mins in $M$. fragrans on the contrary are less prominent suggesting that the chemical constituents of both plants vary nonetheless some compounds are found in common.

Table 1 summarises the compositions of some chemical compounds identified in P. betle and $M$. fragrans. The combined extracts attained the features of both with five compounds identified in common; these include $\beta$ phellandrene, linalool, $\alpha$-terpineol, eugenol and $\alpha$-cadinol. There are also unique compounds to each extract; combining the essential oil as a result produces a mixture with richer chemical compositions. For example, the well reported antifungal compounds, $\alpha$-humulene and $\beta$-elemene, are distinctively found in $P$. betle whilst 1,8 cineole and $p$-cymene are unique to $M$. fragrans. In the mixture, they present concurrently implying possible synergistic effect that could lead to improved antimicrobial selectivity and efficacy (Hossain et al. 2008); this is also demonstrated in the findings of Henry et al. (2009). Despite the additive effects, some compounds identified in the single isolate are interestingly absent in the 


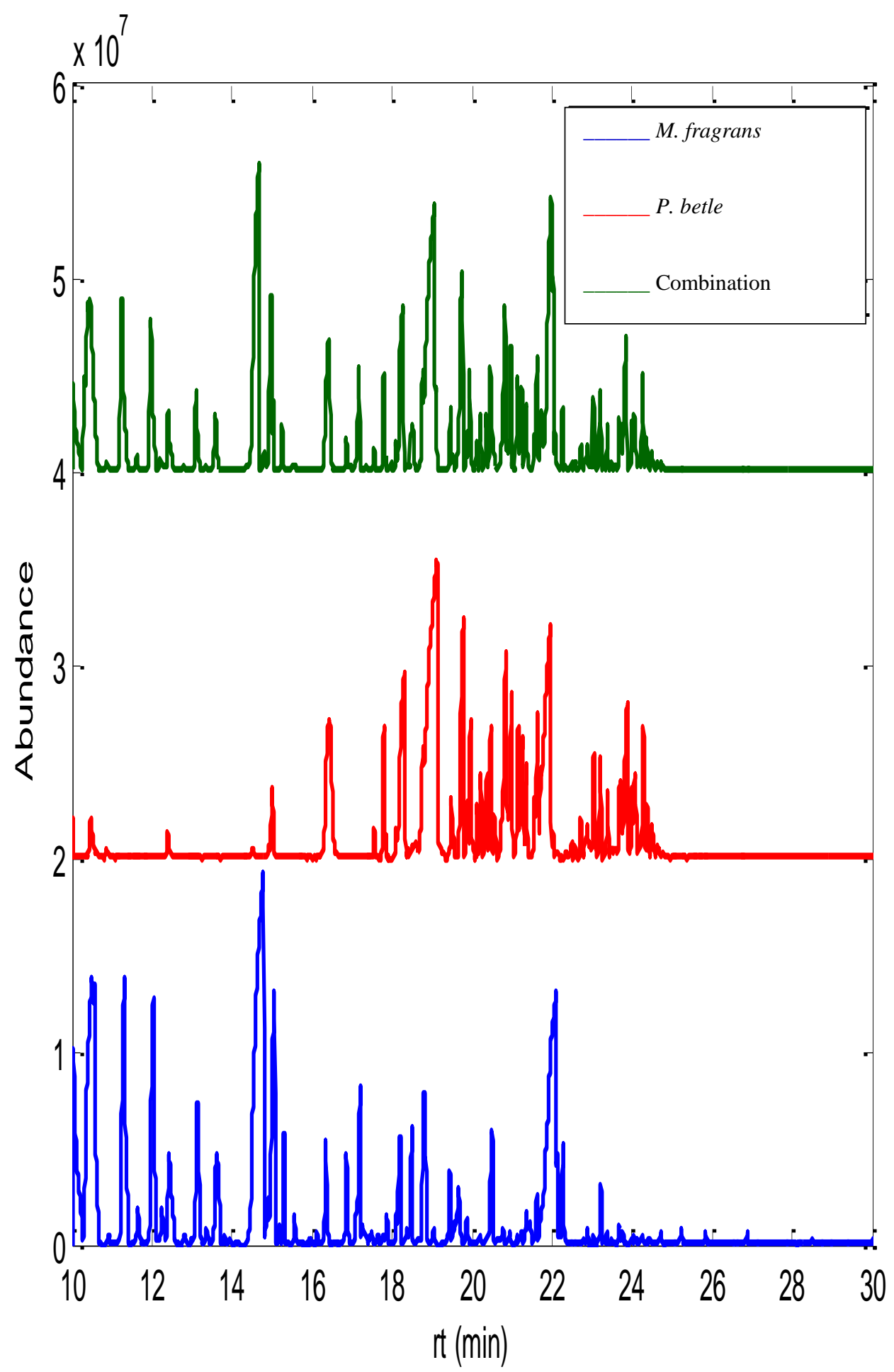

Figure 1. GC chromatograms of single and combined essential oil of P. betle and M. fragrans 
Table 1. Some compounds identified in single and blended essential oils of M. fragrans and P. betle

\begin{tabular}{|c|c|c|c|c|}
\hline Compounds & $\begin{array}{l}\text { Retention } \\
\text { time, min }\end{array}$ & M. fragrans (\%) & P. betle (\%) & Combined (\%) \\
\hline Camphene & 10.04 & 4.39 & nd & 2.53 \\
\hline$p$-cymene & 10.50 & 7.40 & nd & 2.27 \\
\hline$\beta$-phellandrene & 11.32 & 5.51 & 1.01 & 3.69 \\
\hline 1,8-cineole & 11.64 & 1.54 & nd & 0.86 \\
\hline Linalool & 12.42 & 3.11 & 1.75 & 1.98 \\
\hline$\alpha$-terpineol & 15.06 & 4.67 & 2.62 & 2.90 \\
\hline trans-piperitol & 15.30 & 2.14 & nd & 1.18 \\
\hline$\beta$-citronellol & 15.56 & 1.15 & nd & - \\
\hline Chavicol & 16.43 & 5.39 & nd & 3.47 \\
\hline Borneol & 16.86 & 2.06 & nd & 1.08 \\
\hline Safrole & 17.21 & 3.18 & nd & 2.09 \\
\hline$\gamma$-elemene & 17.80 & nd & 3.13 & 1.78 \\
\hline$\alpha$-terpinolene & 17.85 & 1.21 & nd & 0.60 \\
\hline 4-allylphenyl acetate & 18.30 & nd & 5.90 & 3.61 \\
\hline Eugenol & 18.50 & 2.62 & 1.63 & 1.79 \\
\hline Caryophyllene & 19.79 & nd & 5.23 & 4.04 \\
\hline Humulene & 20.47 & nd & 3.01 & 2.37 \\
\hline Ylangene & 21.15 & nd & 3.32 & 1.89 \\
\hline$\alpha$-muurolene & 21.25 & nd & 3.43 & 2.06 \\
\hline$\alpha$-amorphene & 21.35 & nd & 2.70 & 1.76 \\
\hline Myristicin & 21.75 & 7.67 & nd & nd \\
\hline Eugenol acetate & 22.00 & nd & 9.69 & nd \\
\hline Elemicin & 22.28 & 2.33 & nd & 1.48 \\
\hline$\beta$-elemene & 22.73 & nd & 1.71 & 0.99 \\
\hline Elixene & 23.05 & nd & 2.72 & 1.57 \\
\hline $\begin{array}{l}\text { 2-acetyloxy-4-allyphenyl } \\
\text { acetate }\end{array}$ & 23.89 & nd & 4.13 & 2.74 \\
\hline$\alpha$-cadinol & 24.25 & 0.71 & 3.12 & 1.93 \\
\hline Myristic acid & 25.84 & 0.82 & nd & nd \\
\hline
\end{tabular}

Key: "nd" indicates not detected.

blended extract. For example, myristicin and eugenol acetate are eluted in $M$. fragrans and $P$. betle, respectively, at similar retention time with prominent abundance. These compounds are found to co-elute in the mixture where the peak detected fails to be matched with the typical mass spectrum of myristicin or eugenol acetate according to the similarity percentage of $90 \%$.

Figure 2 shows the mass spectra of myristicin and eugenol acetate detected in $M$. fragrans and $P$. betle. The mass spectrum of the compound eluted in the mixture is $87 \%$ and $84 \%$ similar to myristicin and eugenol acetate, respectively. This confusion resulting from co-elution suggests that the operating conditions would require further optimization.

Table 2 summarises the antibacterial activity of single and blended essential oils against $S$. aureus and E. coli at 10, 20 and $50 \mathrm{mg} / \mathrm{mL}$. No statistical significance is deduced between the inhibitory diameters of single and blended essential oils $(p>0.05)$. Comparing the performance with the positive control, streptomycin, the inhibitory activity of $P$. betle is considerably encouraging especially on 


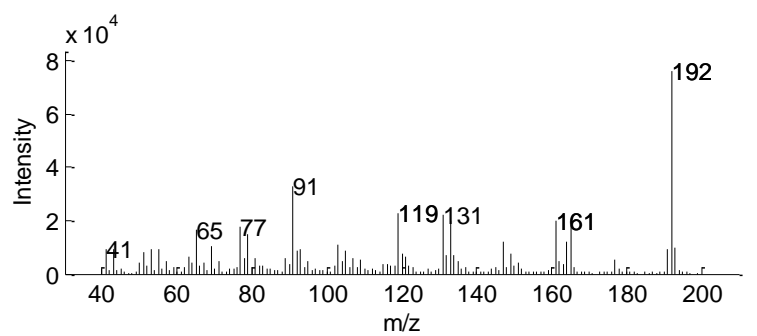

Myristicin in M. fragrans $(21.75 \mathrm{~min})$

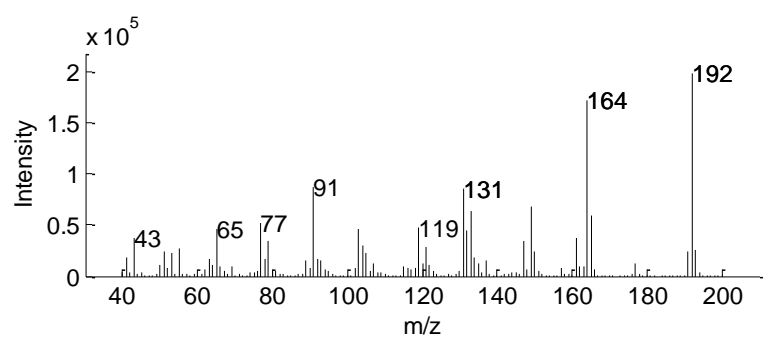

The peak eluted in the mixture $(21.98 \mathrm{~min})$

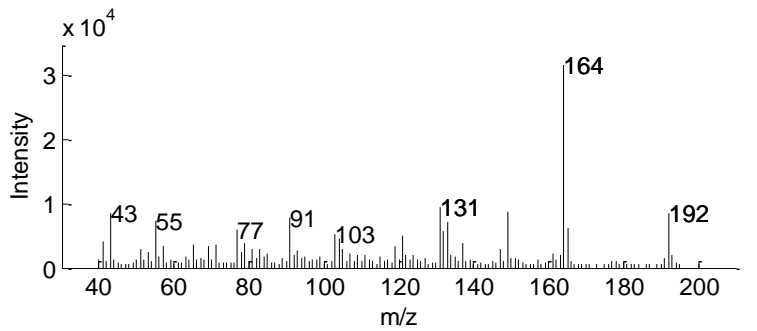

Eugenol acetate in $P$. betle $(22.00 \mathrm{~min})$

Figure 2. Mass spectra of myristicin, eugenol acetate and the peak detected in the mixture at similar retention time.

S. aureus. Penicillin however is relatively less effective. For M. fragrans, weak antibacterial activity is seen on $E$. coli with no inhibition identified on $S$. aureus. This observation concurs the finding of Ameen (2012) where gram positive bacteria are evidenced to be more resistant due to the presence of extra layer of protection restricting the diffusion of hydrophobic compounds (Prabuseenivasan et al. 2006). The lower inhibitory effect of $M$. fragrans does not deny its antibacterial activity but may suggest that the effective concentration have not been attained. The combined essential oil demonstrates enhanced antimicrobial activity although statistically insignificant; this may be associated to the complementary effects of the chemical compounds present in both plants. According to literature, eugenol and linalool are compounds with moderate antibacterial activity; other compounds such as camphene, p-cymene, caryophellene, terpinene, chavicol are reported with weak inhibition property (Damián-Badillo et al. 2008; Fabri et al. 2012). Safrole and $\alpha$-terpineol on the other hand possess relatively greater activity than the aforementioned weak antibacterial compounds (Jantan et al. 2008). The presence of these compounds corroborates the antibacterial property of the extracts. Both $M$. fragrans and $P$. betle exhibit affirmative antifungal activity where treatments at varying concentrations demonstrate statistical significance $(p<0.05)$. The results imply that $P$. betle is stronger than $M$. fragrans; when the extracts are combined, the antifungal performance is improved nonetheless no significant different is corroborated statistically. It is speculated that no antagonistic effects are present as the antimicrobial activity of the combined extract is unhampered on the contrary improved compared to the single extracts.

borneol, 
Table 2. The antibacterial activity of essential oil of M. fragrans and P. betle against E. coli and S. aureus

\begin{tabular}{|c|c|c|c|}
\hline Sample & $\mathrm{mg} / \mathrm{mL}$ & $\begin{array}{c}\text { Inhibition zone }(\mathrm{mm}) \\
\text { E. coli }\end{array}$ & $\begin{array}{c}\text { Inhibition zone }(\mathrm{mm}) \\
\text { S. aureus }\end{array}$ \\
\hline \multirow[t]{3}{*}{ P. betle } & 10 & 8 & - \\
\hline & 20 & 10 & 9 \\
\hline & 50 & 10 & 10 \\
\hline \multirow{3}{*}{ M. fragrans } & 10 & - & - \\
\hline & 20 & 8 & - \\
\hline & 50 & 7 & - \\
\hline \multirow[t]{3}{*}{ Combined } & 10 & - & - \\
\hline & 20 & 10 & 10 \\
\hline & 50 & 11 & 10 \\
\hline \multirow{2}{*}{\multicolumn{2}{|c|}{$\begin{array}{l}\text { Positive control } \\
\text { (Streptomycin) }\end{array}$}} & & \\
\hline & & 18 & 12 \\
\hline & & - & 8 \\
\hline $\begin{array}{l}\text { Negative control } \\
\text { (DMSO) }\end{array}$ & & - & - \\
\hline
\end{tabular}

Key: “_"indicates no observable inhibition zone.

Table 3. The antifungal activity of essential oil of $M$. fragrans and $P$. betle against A. flavus

\begin{tabular}{lccc}
\hline Sample & $\mathrm{mg} / \mathrm{mL}$ & Diameter $(\mathrm{mm})$ & \% Inhibition \\
\hline P. betle & 10 & 54 & 13 \\
& 20 & 50 & 19 \\
M. fragrans & 50 & 38 & 39 \\
& 10 & 58 & 6 \\
Combined & 20 & 50 & 19 \\
& 50 & 46 & 26 \\
Control (DMSO) & 10 & 50 & 19 \\
& 20 & 45 & 27 \\
\hline
\end{tabular}

Key: “_“ indicates no observable inhibition zone.

\section{CONCLUSIONS}

Variation is identified between the chemical compositions of volatile extracts from $P$. betle and $M$. fragrans, the latter contains more eluting compounds at the earlier retention time for example, camphene, $p$-cymene and 1,8cineole. When the extracts are combined, the mixture is characterised by a wider range of chemical constituents suggesting possible additive effects and a broader spectrum of antimicrobial resistance. Generally, $P$. betle demonstrates stronger antimicrobial activity than $M$. fragrans. The antifungal performance is enhanced when the extracts are combined. Although the differences are not statistically supported, the elevated inhibitory activity is observed when the concentration is increased and the extracts are blended.

\section{ACKNOWLEDGEMENTS}

This paper is a result of collaboration between MARA Junior Science College (MRSM), Kuching and Universiti Malaysia Sarawak (UNIMAS) for a chemistry project submitted for One-Malaysia Young Scientist Competition (Pertandingan Tunas Saintis SeMalaysia) held in Pontian, Johor on 21-24 September 2012. This project has won the best project award in the competition.

\section{REFERENCES}

Adams, R.P. (1995). Identification of Essential Oil Components by Gas Chromatography/Mass Spectrometry. Carol Stream, IL., USA: Allured. pp. 804. 
Meen S.J. (2012). Antimicrobial activity of nutmeg extracts against Staphylococcus aureus and Escherichia coli. Al-Taqani, 25(2): 259-163.

Rambewela L., Kumaratunga K.G.A. \& Dias K. (2005). Studies on Piper betle of Sri Lanka. Journal of Natural Science Foundation Sri Lanka, 33(2): 133-139.

Damián-Badillo L.M., Salgado-Garciglia R., Martínez-Muñoz R.E. \& MartínezPacheco M.M. (2008). Antifungal properties of some Mexican medicinal plants. The Open Natural Products, 1: 2733.

Das S., Anjeza C. \& Mandal S. (2012). Synergistic or additive antimicrobial activities of Indian spice and herbal extracts against pathogenic, probiotic and food-spoiler microorganisms. International Food Research Journal, 19(3): 1185-1191.

Datta A., Ghoshdastidar S. \& Singh M. (2011). Antimicrobial property of Piper betle leaf against clinical isolates of bacteria. International Journal of Pharma Sciences and Research, 2(3): 104-109.

Dorman H.J.D. \& Deans S.G. (2000). Antimicrobial agents from plants: antibacterial activity of plant volatile oils. Journal of Applied Microbiology, 88(2): 308-316.

Emami S.A., Asili J., Rahimizadeh M., FazlyBazzaz B.S. \& Hassanzadeh-Khayyat M. (2006). Chemical and Antimicrobial Studies of Cupressus sempervirens L. And C. horizentalis Mill. Essential Oils. Iranian Journal of Pharmaceutical Sciences, 2(2): 103-108.

Fabri R.L., Coimbra E.S., Almeida A.C., Siqueira E.P., Alves T.M., Zani C.L. \& Scio E. (2012). Essential oil Mitracarpus frigidus as a potent source of bioactive compounds. Annals of the Brazilian Academy of Sciences, 84(4): 1073-1080.

Henry E.R., Worthington T., Conway B.R. \& Lambert P.A. (2009). Antimicrobial efficacy of eucalyptus oil and 1,8-cineole alone in combination with chlorhexidine digluconate against microoganisms grown in plaktonic and biofilm cultures. Journal of Antimicrobial Chemotherapy, 64(6): 1219-1225.

Hossain M.A., Ismail Z., Rahman A. \& Kang S.C. (2008). Chemical composition and antifungal properties of the essential oils and crude extracts of Orthosiphon stamineus Benth. Industrial Crops and Products, 27: 328-334.

Jantan I., Moharan B.A.K., Santhanam J. \& Jamal J.A. (2008). Correlation between chemical composition and antifungal activity of the essential oils of eight Cinnamomum species. Pharmaceutical Biology, 46(6): 406-412.

Lachowicz, K.J., Jones, G.P., Brigg, D.R., Bienvenu, F.E., Wan, J., Wilcock, A. \& Coventry, M.J. (1998). The synergistic preservative effects of the essential oils of sweet basil (Ocimum basilicum L.) against acid-tolerant food microflora. Letters in Applied Microbiology, 26: 209-214.

Meshkatalsadat M.H., Badri R. \& Zarei S. (2009). Hydro-distillation extraction of volatile components of cultivated Bunium Iuristanicum Rech. from West of Iran, International Journal of PharmTech Research, 1(2): 129-131.

Muchtaridi, Subarnas A., Apriyantono A. \& Mustarichie R. (2011). Identification of compounds in the essential oil of nutmeg seeds (Myristica fragrans Houtt.) that inhibit locomotor activity in mice. International Journal of Molecular Sciences, 11(11): 4771-4781.

Nguefack, J., Tamgue, O., Lekagne Dongmo, J.B., Dakole, C.D., Leth, V., Vismer, H.F., Amwam Zollo, P.H. \& Nkengfack, A.E. (2012). Synergistic action between fractions of essential oil from Cymbopogon citrates, Ocimum gratissimum and Thymus vulgaris against Penicillium expansum. Food Control, 23(2): 377-383.

Pawar P.L. \& Nabar B.M. (2010). Effects of plant extracts formulated in different ointment bases on MDR strains. Indian Journal of Pharmaceutical Science, 72(3): 397-401. 
Prabuseenivasan S., Jayakumar M. \& Ignacimuthu S. (2006). In vitro antibacterial activity of some plant essential oils. Complementary and Alternative Medicine, 6: 39-46.

Serrano, M.C., Ramfrez, M., Morilla, D., Valverde, A., Chavez, M., Espinel-Ingroff, A., Claro, R., Fernandez, A., Almeida, C. \& Martin-Mazuelos, E. (2004). A comparative study of the disc diffusion method with the broth microdilution and Etest methods for voriconazole susceptibility testing of Asperigillus spp. Journal of Antimicrobial Chemotherapy, 53(5): 739:742.
Suprapta D.N. \& Khalimi K. (2012). Antifungal activities of selected tropical plants from Bali Island. Phytopharmacology, 2(2): 265-270. 
